\title{
Root Mucilage from Pea and Its Utilization by Rhizosphere Bacteria as a Sole Carbon Source
}

\author{
Emma M. Knee, ${ }^{1}$ Fang-Chen Gong, ${ }^{1}$ Mensheng Gao, ${ }^{1}$ Max Teplitski, ${ }^{1}$ Angela R. Jones, ${ }^{2}$ \\ Angel Foxworthy, ${ }^{2}$ Andrew J. Mort, ${ }^{2}$ and Wolfgang D. Bauer ${ }^{1}$ \\ ${ }^{1}$ Department of Horticulture and Crop Science, The Ohio State University, 2021 Coffey Road, Columbus \\ 43210, U.S.A.; ${ }^{2}$ Department of Biochemistry and Molecular Biology, Oklahoma State University, Stillwater \\ 74078, U.S.A. \\ Submitted 16 October 2000; Accepted 2 March 2001.
}

Plant roots secrete a complex polysaccharide mucilage that may provide a significant source of carbon for microbes that colonize the rhizosphere. High molecular weight mucilage was separated by high-pressure liquid chromatography gel filtration from low molecular weight components of pea root exudate. Purified pea root mucilage generally was similar in sugar and glycosidic linkage composition to mucilage from cowpea, wheat, rice, and maize, but appeared to contain an unusually high amount of material that was similar to arabinogalactan protein. Purified pea mucilage was used as the sole carbon source for growth of several pea rhizosphere bacteria, including Rhizobium leguminosarum 8401 and 4292, Burkholderia cepacia AMMD, and Pseudomonas fluorescens PRA25. These species grew on mucilage to cell densities of threeto 25-fold higher than controls with no added carbon source, with cell densities of 1 to $15 \%$ of those obtained on an equal weight of glucose. Micromolar concentrations of nod gene-inducing flavonoids specifically stimulated mucilage-dependent growth of $R$. leguminosarum 8401 to levels almost equaling the glucose controls. $R$. leguminosarum 8401 was able to hydrolyze $p$-nitrophenyl glycosides of various sugars and partially utilize a number of purified plant polysaccharides as sole carbon sources, indicating that $R$. leguminosarum 8401 can make an unexpected variety of carbohydrases, in accordance with its ability to extensively utilize pea root mucilage.

Additional keywords: glycanase, naringenin, symbiotic plasmid.

Root mucilage is the high molecular weight material in plant root exudates. Previous studies have shown that root mucilage from several plant species is composed of approximately 95 to $97 \%$ sugars and 3 to 5\% amino acids (Bacic et al. 1986; Chaboud 1983; Chaboud and Rougier 1984; Moody et al. 1988). The studies by Bacic et al. (1986) and Moody et al. (1988) offer the most sophisticated, rigorous, and complete analyses of root mucilage presently available. The initial study (Bacic et al. 1986) analyzed the sugar composition of maize root mucilage, showing that starch from lysed cells could be a

Corresponding author: W. D. Bauer; Telephone: +1-614-292-9035; E-mail: bauer.7@osu.edu significant contaminant, that the mucilage contained minor quantities of ferulic acid and related phenolics, and that maize mucilage contains a small amount (3\%) of uronic acid as well as the six neutral sugars identified previously by Chaboud (1983). Most importantly, Bacic and colleagues (1986) provided the first glycosidic linkage analysis of a root mucilage. The glycosidic linkages between sugar residues in maize mucilage proved to be surprisingly complex. The galactose, glucose, arabinose, fucose, and xylose residues in maize mucilage were all present in three or four different patterns of glycosidic linkage to other sugars. Overall, the diversity of linkages in the mucilage was almost as great as the diversity of linkages among sugars in the various polysaccharides of plant cell walls (Zablackis et al. 1995). On the basis of glycosidic linkage patterns in mucilage from maize, rice, wheat, and cowpea, it seems likely that the mucilage from each plant species comprises different, and possibly unique, sets of hetropolysaccharides and glycoproteins. In no case, however, were the polymers that make up a root mucilage separated and characterized.

Mucilage is secreted primarily by root cap cells and "border" cells, which detach and differentiate from the cap (Hawes and Brigham 1992). The mucilage secreted by these cells and young root epidermal cells can form a layer over the surface of the younger parts of the root and may diffuse into the surrounding soil to help form a "rhizosheath" of aggregated soil particles (Greaves and Darbyshire 1972; McCully 1995; Perkins et al. 1984). The function(s) of root mucilage remain to be firmly established, although mucilage is most commonly thought to act as a lubricant to protect the root tip as it pushes through the soil (Greenland 1979). Studies also have indicated that root mucilage enhances the stability of soil aggregates (Morel et al. 1987; Morel et al. 1991), and it has been suggested that mucilage may carry gravitropic signals from the root cap to the root tip (Moore et al. 1990) and may protect roots from the toxicity of aluminum and other ions (Horst et al. 1982; Mensch et al. 1987).

It has been estimated that approximately 20 to $25 \%$ of the total reduced carbon released by maize roots is in the form of high molecular weight root mucilage (Chaboud 1983). Thus, mucilage may represent a significant carbon source for soil microbes. Crude high molecular weight maize mucilage was mineralized after its addition to nonsterile soil (Mary et al. 1993), indicating that mucilage can be degraded and utilized at reasonable rates by microbes in the soil. The extent to 
which root mucilage can be degraded by specific soil or rhizosphere microbes, however, has not been investigated nor is it known whether the ability of microbes to utilize root mucilage to support growth is rare or common among soil and rhizosphere species. The ability to utilize root mucilage as a carbon source may be an important factor in the competitive colonization of roots by beneficial and pathogenic rhizosphere microbes. In addition, any microbial degradation of root mucilage could affect proposed mucilage functions such as lubrication, signal transmission, and protection from toxic metal ions.

We sought to learn more about the role of root mucilage in plant-microbe interactions by determining the ability of various rhizosphere bacteria to utilize purified mucilage from pea as the sole carbon source. Rhizobium leguminosarum was one of the bacteria selected for testing. This bacterium establishes a highly coevolved and intimate $\mathrm{N}$-fixing symbiosis with pea, clover, or bean, depending upon which symbiotic plasmid it carries (Downie et al. 1983; Johnston et al. 1978). The ability of $R$. leguminosarum to infect and nodulate roots requires the activation of nodulation genes in the bacteria by flavonoid compounds such as naringenin or luteolin that are secreted by the host (Long 1996; Peters and Verma 1990). Two other bacteria associated with pea roots also were tested for growth on pea mucilage. Burkholderia cepacia AMMD and Pseudomonas fluorescens PRA25 protect pea effectively from Pythium spp. damping off and Aphanomyces spp. root rot (King and Parke 1993; Parke et al. 1991). P. fluorescens PRA25 also was shown to be a good colonizer of pea roots (Bowers and Parke 1993). Whereas each of the bacterial species we tested was found to have a limited ability to utilize pea mucilage for growth, $R$. leguminosarum was capable essentially of complete utilization of pea root mucilage when stimulated by the presence of plant flavonoids.

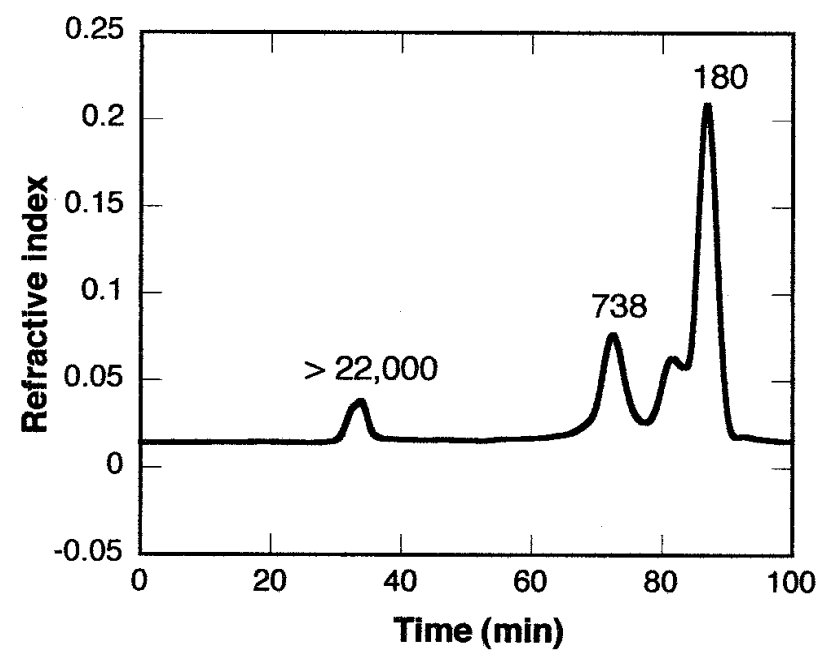

Fig. 1. High-pressure liquid chromatography (HPLC) gel permeation fractionation of pea root exudate. Crude lyophilized pea root rinsate was dissolved in buffer and subjected to HPLC gel permeation analysis, as described in text. The approximate molecular weights of material eluting in each of the peaks detected by refractive index were determined by comparing labeled pullulan standards of known size and are indicated by numbers above the peaks. The material eluting in the void volume peak (fractions $35-40$ ) is purified pea root mucilage.

\section{RESULTS}

Isolation and characterization of purified pea mucilage.

Fractionation of crude pea root exudate by gel filtration high-pressure liquid chromatography (HPLC) (Fig. 1) revealed a small peak of material in the void volume fractions (27 to 43), which eluted with a molecular weight of greater than 20,000 daltons, as determined by comparison with molecular weight standards. The material recovered from these pooled fractions accounted for approximately $4 \%$ by weight of the crude lyophilized root exudate. This high molecular weight material is referred to as "purified root mucilage" and is used for all subsequent chemical and microbiological analyses of mucilage.

Arabinose and galactose accounted for over $60 \%$ of the sugars detected (Table 1). Pea mucilage also contained significant amounts of glucuronic and galacturonic acids as well as the neutral sugars common to plant cell walls. The glycosidic linkage composition of pea mucilage (Table 2) shows that over 20 different linkage types were present at 1 mole $\%$ or greater of the total recovered residues. The amino acid composition of purified pea mucilage is in Table 3 .

Gel filtration of crude pea exudate separated two other peaks of material, in addition to the high molecular weight mucilage peak (Fig. 1). A large peak of low molecular weight compounds such as sugars, salts, and amino acids eluted in the included volume. The third peak (fractions 58 to 77) was intermediate in the amount of material detectable by refractive index and eluted with an apparent molecular weight of approximately 800 daltons. The material in this middle peak was analyzed by ${ }^{1} \mathrm{H}$ and ${ }^{13} \mathrm{C}$ NMR, FAB MS, and 2D-COSY-NMR (data not shown) and found to have a structure consistent with $\gamma$-glutamyl alanine, which was reported previously to be a component of pea root exudate (Kuo et al. 1982; Van Egeraat 1975). For unknown reasons, this dipeptide was not separated readily from the high molecular weight mucilage by extensive dialysis, and it eluted as though it were a considerably higher molecular weight compound during gel filtration. $R$. leguminosarum 8401 cells were able to grow on this HPLCpurified $\gamma$-glutamyl alanine fraction as a sole carbon source and reached almost the same cell numbers as they did on an equal weight of glucose, although growth rates were slower (data not shown).

\section{Recovery of root mucilage.}

The amount of purified mucilage recovered from 1-weekold pea seedling roots was quite low, only about $2 \mu \mathrm{g}$ per seedling, making chemical and microbiological studies difficult. Efforts to recover additional mucilage by extended root rinsing in water and further washing of the sand were not successful. Growth of the seedlings in a hydroponic apparatus gave similar yields of purified mucilage with the same sugar composition (data not shown), thus binding of mucilage to sand or roots or slow solubilization may not account for low recoveries. Likewise, there was no evidence for significant autolysis of mucilage by root enzymes that could account for low recoveries by degradation (see below). Growth of the seedlings in light had no appreciable effect on the amount or composition of the recovered mucilage (data not shown).

The weight of mucilage material recovered after dialysis to remove low molecular weight substances was approximately 
five times higher than that obtained after gel-filtration HPLC (data not shown). The higher recovery after dialysis, however, primarily was the result of the retention of $\gamma$-glutamyl alanine by the membrane used $(12,000$ to 14,000 molecular weight cutoff), despite extensive dialysis (twice for $24 \mathrm{~h}$ against 2 liters of sterile $50 \mathrm{mM}$ HEPES buffer [pH 7.0] containing $0.02 \%(\mathrm{wt} / \mathrm{vol})$ sodium azide at $4^{\circ} \mathrm{C}$, then against sterile tap water for $24 \mathrm{~h}$ and twice for $24 \mathrm{~h}$ against sterile doubledistilled water).

Lyophilization of the purified mucilage was found to reduce recovery. About 30 to $50 \%$ of the lyophilized material was insoluble upon resuspension in water or in $\mathrm{pH} 5.5$ acetate buffer (the solvent used for initial HPLC purification of the mucilage). No consistent difference was found in the sugar compositions of the soluble and insoluble mucilage material (data not shown), thus the chemical basis for the insolubility of some of the mucilage after lyophilization is unclear.

\section{Growth of bacteria on purified root mucilage.}

$R$. leguminosarum 8401 grew on $0.1 \%$ purified pea root mucilage to about $16 \%$ of the cell numbers seen on $0.1 \%$ glucose (Fig. 2A). This growth was about 25 times higher than the controls, with no added carbon. R. leguminosarum 8401 (pRL1JI) grew to $13 \%$ of the cell numbers in glucose controls (Fig. 2B) on purified pea mucilage, similar to the growth of 8401 cells carrying no symbiotic plasmid.

Because expression of symbiotic nodulation (nod) genes in rhizobia is stimulated by the presence of host-root-secreted flavonoids (Peters and Verma 1990), we sought to determine whether the addition of flavonoids had any effect on the ability of $R$. leguminosarum 8401 to utilize pea mucilage for growth. The presence of $1 \mu \mathrm{M}$ naringenin stimulated $R$. leguminosarum 8401 and $R$. leguminosarum 8401 (pRL1JI) to reach maximum cell densities on mucilage that were approximately 75 and $45 \%$ of the maximal cell densities of glucosegrown cultures, respectively (Fig. 2). The stimulatory effects of naringenin were not evident until 3 or 4 days after starting the cultures. Microscopic observations revealed that the gradual reduction in countable colony-forming units in older cultures of the glucose controls (Fig. 2) was the result of cell clumping, not cell death (data not shown). The mucilagedependent growth of $R$. leguminosarum 8401 (pRL1nod D57::Tn5), a strain carrying the symbiotic plasmid pRL1JI with a mutation in the nodD gene, was stimulated by narin- genin to a similar extent as $R$. leguminosarum 8401 (pRL1JI) (data not shown). Thus, neither the symbiotic plasmid nor NodD, the normal receptor for flavonoid activation of nod genes (Peters and Verma 1990), seems to be required for naringenin enhancement of mucilage utilization. The flavonoids luteolin and 4,7-dihydroxy flavone had similar effects on the ability of $R$. leguminosarum 8401 to utilize pea root mucilage (data not shown).

$R$. leguminosarum bv. phaseoli 4292, a rifampin-resistant sibling of 8401 carrying the symbiotic plasmid conferring nodulation of bean (pRP2JI), also was able to utilize pea root mucilage as a sole carbon source (growth $=8 \%$ of glucose control; Fig. 3). The growth of strain 4292 (= 8401 [pRP2JI]) on pea mucilage was not stimulated by $1 \mu \mathrm{M}$ naringenin.

The two pea root colonizing biocontrol strains $B$. cepacia AMMD and $P$. fluorescens PRA25 also were able to utilize purified pea root mucilage as a sole carbon source, but to a very limited extent (Fig. 4A and B). The addition of naringenin had no significant effect on the ability of these bacteria to use mucilage for growth. When growing on purified mucilage, $B$. cepacia reached maximal cell densities that were three- to fivefold higher than the controls with no added $\mathrm{C}$ but just $1 \%$ of the maximum for the glucose controls, whereas $P$. fluorescens reached maximal cell densities that were sixfold higher than the no-added-C controls and $4 \%$ of the glucose controls.

\section{Growth of bacteria on plant polysaccharides.}

$R$. leguminosarum 8401 and $R$. leguminosarum 8401 (pRL1JI) were able to utilize a number of commercially available plant polysaccharides for growth (Fig. 5). Maximal cell densities varied, depending upon the polysaccharide. Rhamnogalacturonan and debranched arabinan provided the highest final cell densities, whereas pectin and pectic galactan supported much lower levels of growth. Supplementing the culture medium with $10 \mathrm{nM}$ to $1 \mu \mathrm{M}$ naringenin had no significant positive or negative effect on growth rates or growth yields of $R$. leguminosarum 8401 on any of the polysaccharides tested nor on the growth rates or yields of $R$. leguminosarum 8401 on either glucose or NM salts containing no carbon source (data not shown). When tested for the ability to hydrolyze a variety of $p$-nitrophenyl glycosides, $R$. leguminosarum 8401 and 8401 (pRL1J) had similar and appreciable abilities to hydrolyze the $p$-nitrophenyl glycosides of $\alpha-\mathrm{L}$ -

Table 1. Sugar compositions of root mucilages

\begin{tabular}{lrcccc}
\hline & \multicolumn{3}{c}{ Recovered carbohydrate (\%) } \\
\cline { 2 - 6 } Sugar & Pea $^{\mathbf{a}}$ & Cowpea $^{\mathbf{b}}$ & Wheat $^{\mathbf{b}}$ & Maize $^{\mathbf{c}}$ & Rice $^{\mathbf{d}}$ \\
\hline Arabinose & 33.5 & 31.0 & 31.0 & 16.0 & 13.7 \\
Fucose & 0.5 & 9.0 & 3.0 & 21.0 & 5.2 \\
Galactose & 30.5 & 28.0 & 16.5 & 33.5 & 20.3 \\
Galacturonic acid & 5.5 & 11.5 & 3.0 & Trace & Not determined \\
Glucose & 6.0 & 18.5 & 15.0 & 13.0 & 37.9 \\
Glucuronic acid & 7.5 & 0.0 & 1.0 & 3.0 & Not determined \\
Mannose & 7.0 & 6.0 & 1.5 & 2.0 & 4.6 \\
Rhamnose & 5.0 & 2.0 & 33.0 & 0.0 & 0.0 \\
Xylose & 4.0 & 7.0 & & 14.0 & 18.3 \\
\hline
\end{tabular}

\footnotetext{
${ }^{a}$ This study (mole \%).

b Moody et al. 1988; \% wt/wt.

${ }^{\mathrm{c}}$ Bacic et al. 1986; \% wt/wt.

${ }^{\mathrm{d}}$ Chaboud and Rougier 1984; \% wt/wt.
} 
arabinofuranose, $\alpha$-L-rhamnopyranose, $\alpha$-D-galacto-pyranose, $\alpha$-D-mannopyranose, $\beta$-D-xylopyranose and $\alpha$-D-glucopyranose.

\section{DISCUSSION}

\section{Mucilage composition and structure.}

The sugar, amino acid, and glycosidic linkage composition of purified mucilage from pea is similar, in many respects, to the composition of root mucilage from maize, rice, wheat, and cowpea (Tables 1, 2, and 3). The sugar composition of pea mucilage was most similar to that of cowpea, although cowpea mucilage had considerably higher amounts of fucose and glucose but none of the glucuronic acid found in pea mucilage. Similar to cowpea mucilage, the mucilage from pea was rich in uronic acids $(11.5 \%$ by weight in cowpea mucilage versus $13 \%$ mole in pea mucilage), three to four times the levels found in the mucilage from the monocot species. The functional consequences of such highly acidic mucilage are unclear.

The glycosidic linkage composition of pea root mucilage was quite complex and generally similar to that of root mucilage from other plant species, particularly that of cowpea. Pea and cowpea root mucilage were most similar in the high amounts of terminal arabinose residues, 5-linked arabinose residues, and 3-, 6- and 3,6-linked galactosyl residues. Such glycosidic linkages are found commonly in arabinogalactan proteins (AGPs) (Bacic et al. 1996; Fincher et al. 1983; Sims et al. 2000), as are galacturonic acid and hydroxyproline, which are both present in particularly high amounts in pea mucilage. It is thus tempting to speculate that pea root mucilage may be composed primarily of AGPs. AGPs have been identified by chemical and antigenic tests in the mucilage from maize (Bacic et al. 1986) and on pea roots (Gollotte et al. 1995). They are recognized for their high-water-binding and gel-formation properties (Fincher et al. 1983), which

Table 2. Glycosidic linkage compositions of purified root mucilages

\begin{tabular}{|c|c|c|c|c|c|}
\hline \multirow[b]{2}{*}{ Monosaccharide } & \multirow[b]{2}{*}{ Deduced glycosidic linkage } & \multicolumn{4}{|c|}{ Recovered carbohydrate (mole \%) } \\
\hline & & $\mathbf{P e a}^{\mathbf{a}}$ & Cowpea $^{b}$ & Wheat $^{\mathrm{b}}$ & Maize $^{c}$ \\
\hline Arabinose $(f)$ & $\begin{array}{l}\text { Terminal } \\
\text { 2-linked } \\
\text { 3-linked } \\
\text { 5-linked } \\
\text { 3,5-linked } \\
\text { 2,3,5-linked }\end{array}$ & $\begin{array}{r}17 \\
- \\
1 \\
11 \\
1 \\
2\end{array}$ & $\begin{array}{l}10 \\
0.5 \\
4 \\
9 \\
1 \\
5\end{array}$ & $\begin{array}{c}22 \\
1 \\
1 \\
1.5 \\
- \\
2\end{array}$ & $\begin{array}{c}4 \\
6 \\
- \\
\text { Trace } \\
- \\
-\end{array}$ \\
\hline $\operatorname{Arabinose}(p)$ & Terminal & - & Trace & - & 1 \\
\hline Galactose $(p)$ & $\begin{array}{l}\text { Terminal } \\
\text { 2-linked } \\
\text { 3-linked } \\
\text { 4-linked } \\
\text { 6-linked } \\
\text { 2,3-linked } \\
\text { 2,6-linked } \\
\text { 3,4-linked } \\
\text { 3,6-linked } \\
\text { 3,4,6-linked }\end{array}$ & $\begin{array}{r}4 \\
- \\
11 \\
- \\
5 \\
- \\
- \\
8 \\
10 \\
-\end{array}$ & $\begin{array}{c}3 \\
\text { Trace } \\
10 \\
2 \\
6 \\
- \\
- \\
0.5 \\
14 \\
1\end{array}$ & $\begin{array}{c}3 \\
- \\
3 \\
- \\
2 \\
- \\
- \\
- \\
11 \\
-\end{array}$ & $\begin{array}{c}4 \\
8 \\
3 \\
- \\
\text { Trace } \\
6 \\
\text { Trace } \\
- \\
7 \\
-\end{array}$ \\
\hline Fucose $(p)$ & $\begin{array}{l}\text { Terminal } \\
\text { 2-linked } \\
\text { 3-linked }\end{array}$ & $\begin{array}{l}- \\
- \\
-\end{array}$ & $\begin{array}{l}3 \\
- \\
-\end{array}$ & $\begin{array}{l}0.5 \\
- \\
-\end{array}$ & $\begin{array}{c}14.5 \\
1.5 \\
8\end{array}$ \\
\hline $\operatorname{Rhamnose}(p)$ & $\begin{array}{l}\text { Terminal } \\
\text { 2-linked }\end{array}$ & $\begin{array}{l}1 \\
-\end{array}$ & $\begin{array}{l}0.5 \\
0.5\end{array}$ & $\begin{array}{l}- \\
-\end{array}$ & $\begin{array}{l}- \\
-\end{array}$ \\
\hline Glucose $(p)$ & $\begin{array}{l}\text { Terminal } \\
\text { 3-linked } \\
\text { 4-linked } \\
\text { 6-linked } \\
\text { 4,6-linked } \\
\text { 2,4,6-linked }\end{array}$ & $\begin{array}{l}8 \\
? \\
? \\
- \\
2 \\
?\end{array}$ & $\begin{array}{l}6 \\
- \\
7 \\
- \\
2.5 \\
-\end{array}$ & $\begin{array}{l}3 \\
1 \\
6 \\
1 \\
3 \\
-\end{array}$ & $\begin{array}{l}\text { Trace } \\
3 \\
5 \\
- \\
7 \\
2\end{array}$ \\
\hline $\operatorname{Mannose}(p)$ & $\begin{array}{l}\text { Terminal } \\
\text { 2-linked } \\
\text { 2,3-linked }\end{array}$ & $\begin{array}{l}- \\
? \\
6\end{array}$ & $\begin{array}{l}0.5 \\
1 \\
0.5\end{array}$ & $\begin{array}{l}- \\
- \\
-\end{array}$ & $\begin{array}{l}- \\
- \\
3\end{array}$ \\
\hline Xylose $(p)$ & $\begin{array}{l}\text { Terminal } \\
\text { 2- and 4-linked } \\
\text { 2,4-linked } \\
\text { 3,4-linked } \\
\text { 2,3,4-linked }\end{array}$ & $\begin{array}{l}- \\
2 \\
- \\
- \\
-\end{array}$ & $\begin{array}{l}6 \\
3 \\
0.5 \\
- \\
3\end{array}$ & $\begin{array}{c}4.5 \\
17 \\
1 \\
7 \\
9\end{array}$ & $\begin{array}{c}8 \\
3 \\
- \\
3 \\
\text { Trace }\end{array}$ \\
\hline
\end{tabular}

a This study. - = not detected; ? = identity of sugar not certain. Unidentified residues include 2-linked hexopyranose $=2 \%$; 3 -linked hexopyranose = $3 \%$; 4-linked hexopyranose $=2 \%$; and 2,4,6-linked hexopyranose $=1 \%$ of the total recovered from pea mucilage.

${ }^{\mathrm{b}}$ Moody et al. 1988 .

c Bacic et al. 1986 
could serve in important ways in lubrication and water retention around the roots. Previous reports (Anderson et al. 1988; Chao et al. 1988) indicate the presence on legume root surfaces of arabinose-galactose-rich glycoproteins (possibly AGPs) that selectively agglutinated saprophytic Pseudomonas spp. strains from pea and bean rhizospheres. This type of agglutination is consistent with the lectin-like properties of AGPs (Fincher et al. 1983; Majewska-Sawka and Nothnagel 2000). If pea mucilage is composed primarily of AGPs, it is unclear whether the terminal glucose, 2,3-linked mannose, and 4,6-linked glucose residues, not commonly found in AGPs, are linked to the AGPs or linked to each other in separate heteropolysaccharides. Preliminary ion exchange chromatographic analysis of purified mucilage indicated that virtually all pea mucilage polymers are acidic, eluting in five relatively well-separated peaks with increasing salt concentration (data not shown).

\section{Utilization of pea mucilage as sole carbon source.}

The results presented above show that the N-fixing symbiont of pea, R. leguminosarum 8401 (pRL1JI), is capable of using purified pea root mucilage and a variety of complex plant polysaccharides as sole carbon sources for growth. When starved $R$. leguminosarum 8401 cells were cultured on minimal salt medium containing purified mucilage, they were able to grow rapidly, at rates comparable to the glucose control for the first day (Fig. 2). This indicates that significant amounts of the carbon and energy present in mucilage polymers were readily accessible to the bacteria. Nevertheless, the majority of the carbon and energy in pea mucilage polymers was inaccessible to $R$. leguminosarum 8401 under these conditions because final cell numbers were approximately sixfold lower than the glucose controls.

In the presence of micromolar concentrations of naringenin or other plant flavonoids, $R$. leguminosarum 8401was able to utilize pea mucilage for growth almost as well (50 to 75\%) as it did with glucose, indicating that most of this bacterium's capabilities for hydrolyzing mucilage are host plant inducible,

Table 3. Amino acid compositions of root mucilage

\begin{tabular}{lcccc}
\hline & \multicolumn{4}{c}{ Mole $^{\text {\% }}$} \\
\cline { 2 - 5 } Amino acid & Pea $^{\mathbf{a}}$ & Cowpea $^{\mathbf{b}}$ & Wheat $^{\mathbf{b}}$ & Maize $^{\mathbf{c}}$ \\
\hline Hyp & 12.9 & Trace & 0.7 & 0.7 \\
Ser & 14.9 & 7.4 & 8.6 & 6.1 \\
Thr & 9.5 & 5.1 & 7.3 & 5.6 \\
Pro & 6.4 & 5.9 & 6.2 & 8.2 \\
Gly & 12.8 & 13.1 & 10.1 & 13.8 \\
Ala & 8.1 & 7.2 & 9.3 & 8.1 \\
His & 0 & 0.9 & 1.9 & 1.5 \\
Cys & 0 & 0.4 & 1.1 & ND \\
Glx & 15.8 & 15.1 & 6.9 & 14.1 \\
Asx & ND & 14.7 & 9.4 & 10.1 \\
Tyr & 4.7 & 1.6 & 3.0 & 1.4 \\
Val & 4.0 & 5.2 & 7.0 & 4.6 \\
Met & 0 & 0.8 & 1.8 & 1.0 \\
Ile & 2.6 & 3.4 & 4.4 & 2.7 \\
Leu & 2.3 & 5.1 & 7.7 & 4.4 \\
Phe & 2.4 & 2.9 & 3.9 & 2.3 \\
Lys & 1.9 & 2.0 & 5.6 & 1.8 \\
Arg & 1.2 & 2.0 & 3.6 & 2.6 \\
\hline
\end{tabular}

${ }^{a}$ This study; ND = not determined.

b Moody et al. 1988 .

c Bacic et al. 1986. as opposed to starvation inducible or constitutive. The onset of flavonoid-induced utilization of mucilage was slow and unapparent until approximately 3 days after suspending the bacteria in the mucilage-flavonoid-mineral salts medium (Fig. 2).
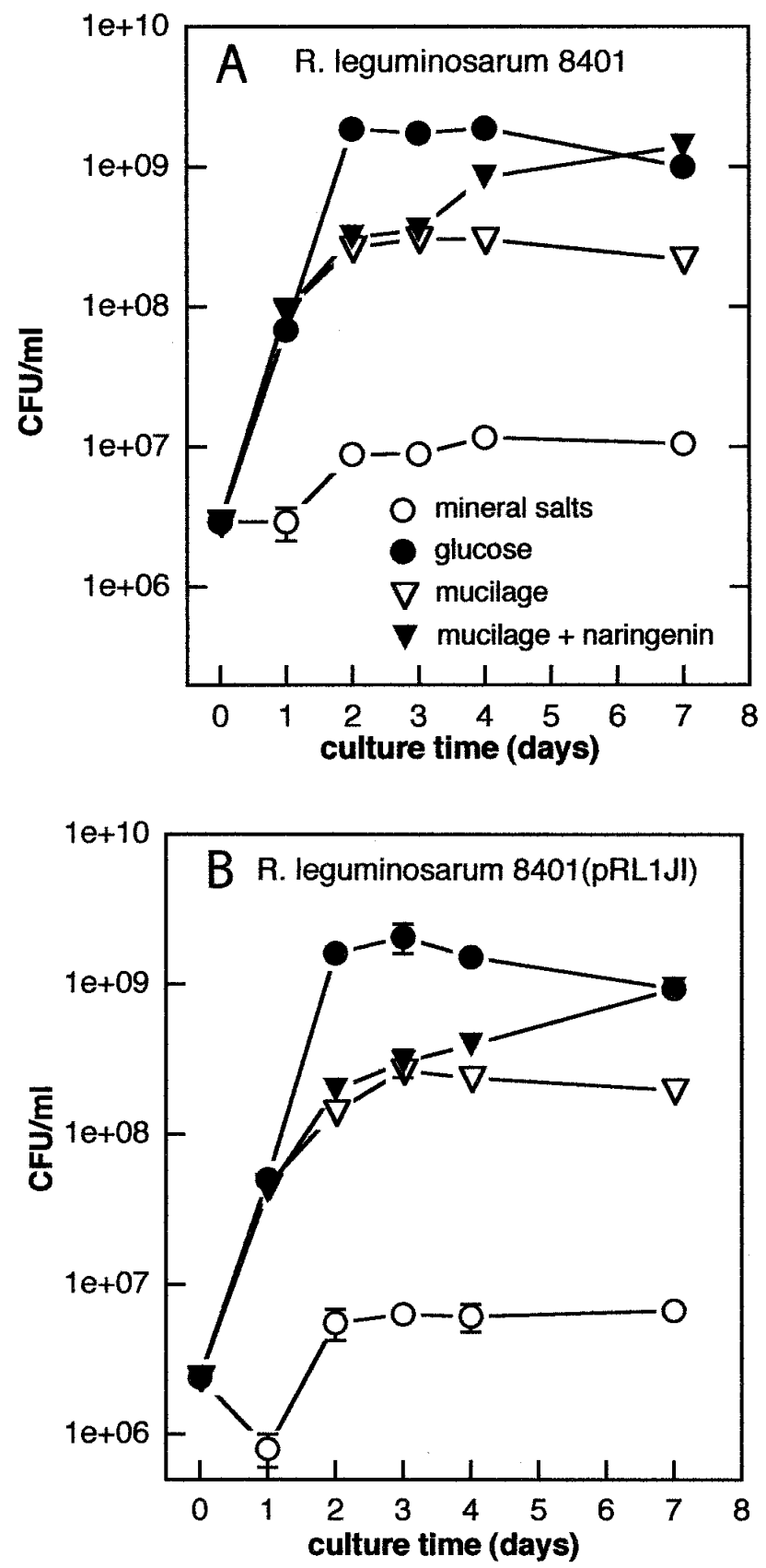

Fig. 2. Growth of Rhizobium leguminosarum 8401 and R. leguminosarum 8401 (pRL1JI) on purified pea root mucilage as the sole carbon source. Cultures of the bacteria were washed, starved for 3 days, then suspended at an initial cell density of approximately $10^{6}$ cells per $\mathrm{ml}$ in mineral salts solution with either no added carbon source or $0.1 \%$ glucose or $0.1 \%$ root mucilage. A, R. leguminosarum 8401. B, R. leguminosarum 8401 (pRL1JI). Growth of these cultures was determined at various intervals by plate counting of colony-forming units. Naringenin was added to replicate cultures (solid triangles) growing on pea mucilage to a final concentration of $1 \mu \mathrm{M}$. Each experiment was performed in duplicate and repeated at least two times with similar results. Error bars indicate standard error limits. 
This suggests that secretion of the necessary enzymes may have been slow and, perhaps, dependent upon higher cell densities or the release of mucilage fragments by initially present enzymes as well as flavonoid. Because $R$. leguminosarum 8401 cells lacking a functional nodD gene or the entire Sym plasmid still showed enhanced mucilage utilization in response to added flavonoid (Fig. 2), the stimulation of mucilage-utilization capabilities by flavonoids clearly involves molecular mechanisms that differ from the well-characterized nodD-mediated stimulation of the lipo-oligosaccharide Nod factor signal synthesis (Long 1996). The flavonoid stimulation of mucilage utilization appears to be quite specific to this carbon source because the flavonoids had no observable effect on the utilization of glucose or the various plant polysaccharides tested. A nodD-independent stimulation of the rate of growth of Sinorhizobium meliloti by various flavonoids has been reported (Hartwig et al. 1991), but the flavonoids did not affect the final cell number.

Because flavonoid-stimulated degradation of pea mucilage was extensive, $R$. leguminosarum 8401 must be able to produce quite a diversity of glycanases, presumably one (or two, $\alpha, \beta)$ for most of the major types of glycosidic linkage in pea mucilage (Table 1). The production of a variety of glycanases is consistent with the ability of the bacterium to grow on the array of plant polysaccharides tested (Fig. 5) and to hydrolyze a variety of $p$-nitrophenyl glycosides. It seems likely that the

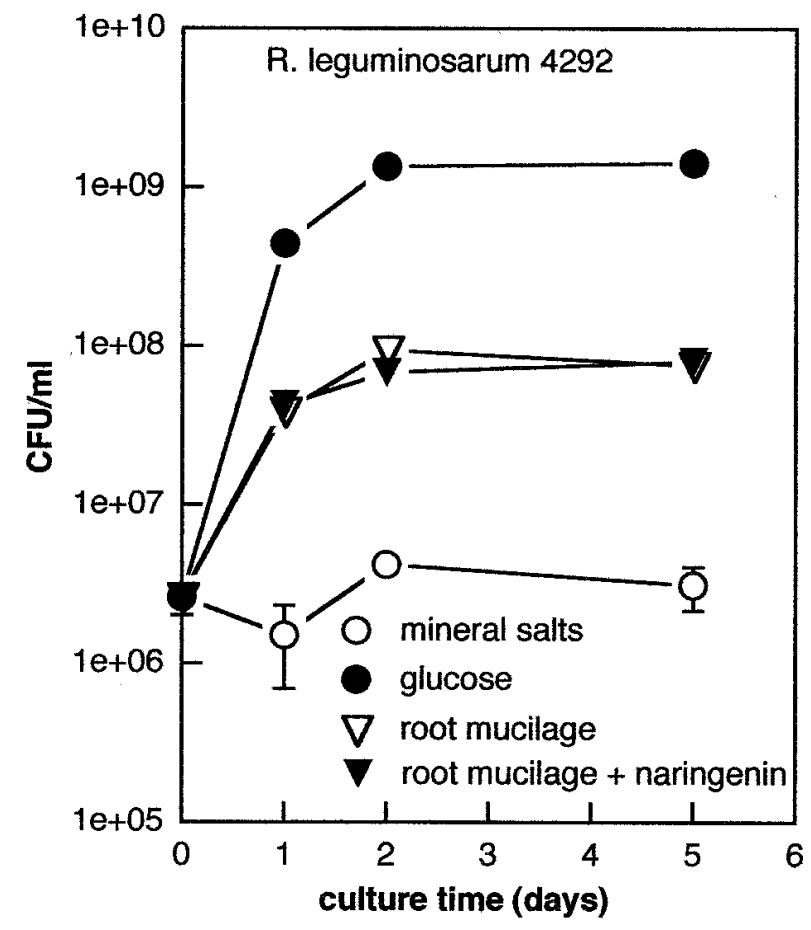

Fig. 3. Growth of Rhizobium leguminosarum 4292 on purified pea root mucilage as the sole carbon source. Cultures of the bacteria were washed, starved for 3 days, then suspended at an initial cell density of approximately $10^{6}$ cells per $\mathrm{ml}$ in mineral salts solution with either no added carbon source or $0.1 \%$ glucose or $0.1 \%$ root mucilage. Growth of these cultures was determined at various intervals by plate counting colony-forming units. Naringenin was added to replicate cultures (solid triangles) growing on pea mucilage to a final concentration of $1 \mu \mathrm{M}$. Each experiment was performed in duplicate and repeated at least two times with similar results. Error bars indicate standard error limits. synthesis of most of the polysaccharide (mucilage)-degrading enzymes of $R$. leguminosarum 8401 is normally repressed and become derepressed under appropriate conditions.

In the past, there has been considerable interest in the synthesis and secretion of polysaccharide-degrading enzymes by rhizobia, with the thought that such enzymes from the bacteria might be essential for locally degrading the host root hair cell walls at the site of penetration and infection (Callaham and Torrey 1981; Dazzo 1981; Dazzo and Hrabak 1981). R. leguminosarum (bv. trifolii), for example, has been shown to synthesize an extracellular pectinase and cellulase (JimenezZurdo et al. 1996; Mateos et al. 1992), enzymes crucial to the maceration of primary cell walls. More recent studies (Finnie et al. 1998; York and Walker 1998; Zorreguieta et al. 2000) suggest that at least some of the extracellular glycanases of rhizobia may instead hydrolyze the bacterium's own exopolysaccharides (EPS). Previous researchers have shown that EPSdeficient mutants of rhizobia cannot invade their host (Cheng and Walker 1998; Leigh and Walker 1994) and that the addition of oligomeric subunits of wild-type EPS can restore such mutants to normal infection ability (Battisti et al. 1992; Djordjevic et al. 1987; Gonzalez et al. 1996). These observations suggest that the extracellular EPS hydrolases of rhizobia might generate oligomeric EPS subunits as signals to the host (Zorreguieta et al. 2000).

Our results suggest that, in addition to EPS hydrolytic activity, $R$. leguminosarum has an array of extracellular glycanases that can contribute to its saprophytic nutrition by releasing sugars from plant polysaccharides. Whether any of these glycanases also are important to the localized lysis or breakage of root hair cell walls at the site of symbiotic penetration remains to be determined.

Further studies are now needed to determine whether the extensive ability of $R$. leguminosarum to degrade and utilize root mucilage and various plant polysaccharides for growth is common among soil and rhizosphere bacteria. A careful analysis of another soil-rhizosphere bacterium, P. fluorescens subsp. cellulosa, has shown that it is capable of producing a substantial diversity of polysaccharide-degrading enzymes, including cellulases, xylanases, and a mannanase, arabaninase, and galactanase (Hazlewood and Gilbert 1998) but there appear to be few other thorough attempts to look for polysaccharide-degrading enzymes among soil-rhizosphere bacteria. The modest ability of $B$. cepacia AMMD and P. fluorescens PRA25 to utilize mucilage (Fig. 4) suggest that many soil and rhizosphere bacteria may be capable of synthesizing at least some enzymes to degrade mucilage or plant wall polysaccharides. It will be interesting to learn more about the environmental conditions necessary to induce the synthesis of such enzymes, the contributions that such enzymes and root mucilage make to bacterial nutrition in rhizosphere environments, and the potential cooperativeness among rhizosphere microbes in utilization of mucilage and other complex plant polysaccharides.

\section{MATERIALS AND METHODS}

\section{Preparation of purified root mucilage.}

Seeds of Little Marvel pea (Pisum sativum) were purchased from W. Atlee Burpee (Warminister, PA, U.S.A.). Seeds were surface sterilized by soaking in $95 \%$ ethanol for $60 \mathrm{~min}$, rinsing 

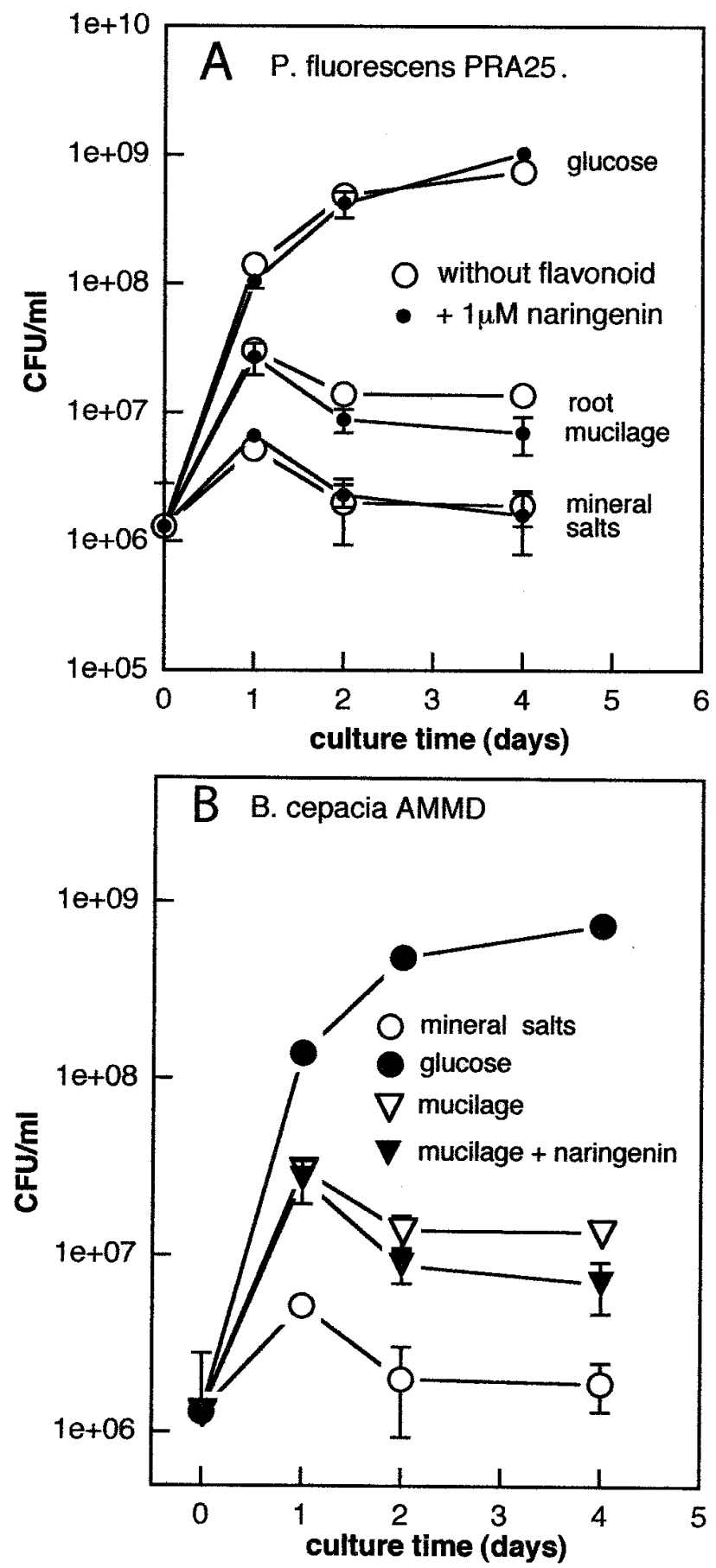

Fig. 4. Growth of Pseudomonas fluorescens PRA25 and Burkholderia cepacia AMMD on purified pea root mucilage as the sole carbon source. Cultures of the bacteria were washed, starved for 3 days, then suspended at an initial cell density of approximately $10^{6}$ cells per $\mathrm{ml}$ in mineral salts solution with either no added carbon source or $0.1 \%$ glucose or $0.1 \%$ root mucilage. A, P. fluorescens PRA25. B, B. cepacia AMMD. Growth of these cultures was determined at various intervals by plate counting of colony-forming units. Naringenin was added to replicate cultures (solid triangles) growing on pea mucilage to a final concentration of $1 \mu \mathrm{M}$. Each experiment was performed in duplicate and repeated at least two times with similar results. Error bars indicate standard error limits. briefly with sterile tap water, then immersing in commercial bleach for $60 \mathrm{~min}$ and rinsing eight to 10 times (10 min each) with sterilized tap water. Sterilization and washing were carried out with gentle shaking on a rotary shaker $(100 \mathrm{rpm})$. The surface-sterilized seeds were then imbibed in sterile tap water for 2 to $4 \mathrm{~h}$ and planted in autoclaved, washed quartz sand (3Q Rock; Columbus Builders Supply, Columbus, OH, U.S.A.) moistened with $15 \%$ (vol/vol) sterile tap water. The seeds were planted in an assembly made by placing a stainless-steel sieve with no. 4 mesh on a 2-quart autoclavable plastic dish (Newell Rubbermaid, Freeport, IL, U.S.A.) filled with wetted sand. The steel mesh was then covered with a layer of cheesecloth, and the sieve was filled with wetted sand to a depth of $0.5 \mathrm{~cm}$ and covered with a second plastic dish. The planting assembly was wrapped in aluminum foil, autoclaved twice for $90 \mathrm{~min}$, and allowed to cool, prior to planting. Seeds were spread on the sand to approximately half-maximal packing density, then covered with a 2-cm layer of wetted, sterile sand. The cover dish was replaced, and the seedlings grown in the dark for 7 to 8 days, at which time the seedling roots had grown to the bottom of the lower dish. Several seeds from each lot also were placed on three TY agar plates (10

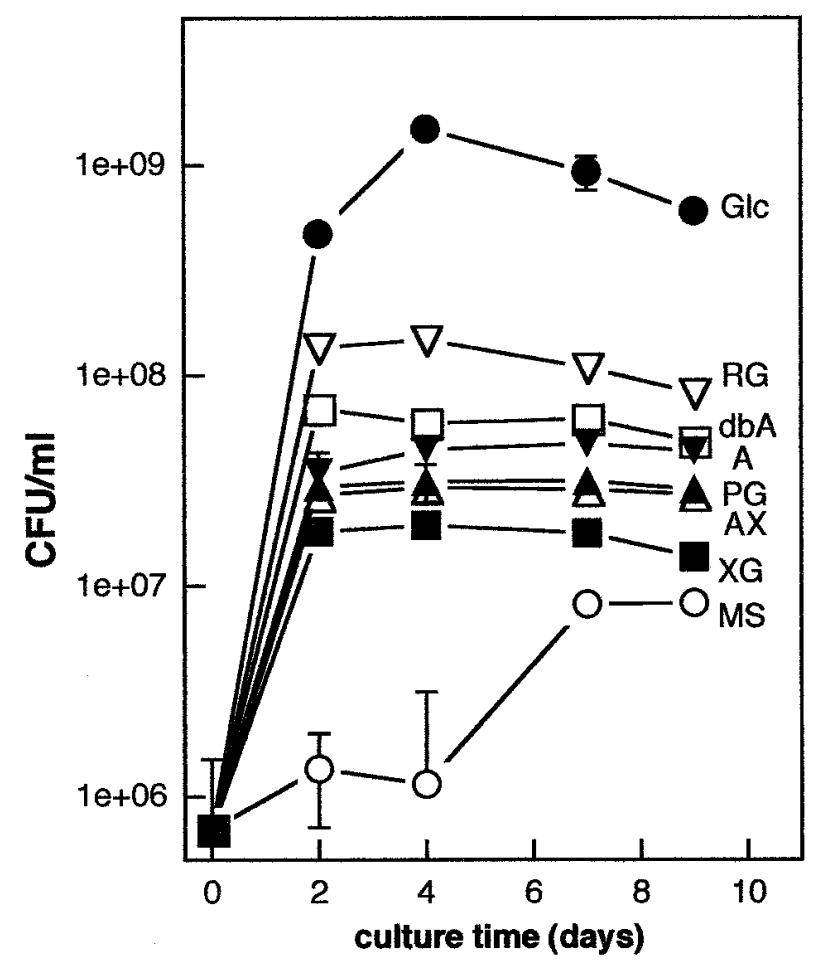

Fig. 5. Growth of Rhizobium leguminosarum 8401 on various plant polysaccharides as the sole carbon sources. Bacteria cultures were washed, starved for 3 days, then suspended at an initial cell density of approximately $10^{6}$ cells per $\mathrm{ml}$ in mineral salts solution with either no added carbon source or $0.1 \%$ glucose or $0.1 \%$ of the indicated plant polysaccharide, as described in text. Polysaccharides used as carbon sources are indicated as RG (open, upside down triangle), rhamnogalacturonan; dbA (open square), debranched arabinan; A (solid, upside down triangle), arabinan; PG (solid triangle), pectic galactan; AX (open triangle), arabinoxylan; XG (solid square), xyloglucan; MS (open circle), mineral salts; and Glc (solid circle), glucose. Growth of these cultures was determined at various intervals by plate counting of colonyforming units. Results are from a single, representative experiment with duplicate cultures. Error bars indicate standard error limits. 
seeds per plate) to check the sterility of the treated seeds. To collect crude root exudate, the steel sieve with seedlings was carefully lifted from the sand in the lower dish, and loose sand was gently but thoroughly dislodged from the root mass by repeated blows to the side of the sieve. The roots were rinsed by placing the sieve onto a cutoff Rubbermaid dish filled with sterile tap water deep enough (usually 300 to $400 \mathrm{ml}$ ) to contact the sand particles that adhered tightly to the root surfaces. A large magnetic stirring bar was used to circulate the water at moderate rpm for approximately $2 \mathrm{~h}$ at $4^{\circ} \mathrm{C}$. The sand particles adhering to the root surfaces gradually fell into the rinse liquid during this time. Roots from a second and third sieve assembly ordinarily were rinsed in the same wash liquid to minimize total volume. When root rinsing was complete, 200- $\mu$ l aliquots were plated onto TY agar to check for possible microbial contamination. If these plates subsequently indicated the presence of more than 100 bacteria per ml, the batch of root rinsate was considered contaminated and discarded. The crude root rinsate was filtered through GFC/A glass fiber paper (Whatman, Kent, U.K.) on a Buchner funnel, then centrifuged twice at $10,000 \times g$ for $10 \mathrm{~min}$, taking care not to disturb the pellet. The supernatant was filtered through a $0.45-\mu \mathrm{m}$ filter membrane (Millipore, Bedford, MA, U.S.A.) to sterilize it. This crude root exudate was concentrated by lyophilization.

To purify the root mucilage, the crude lyophilized root exudate was dissolved in $50 \mathrm{mM}$ ammonium acetate buffer, $\mathrm{pH}$ 5.5, at a concentration of 10 to $20 \mathrm{mg}$ per $\mathrm{ml}$. Any insoluble material was removed by centrifugation prior to HPLC gel filtration on a Toyopearl HW-50 column (Tosoh Biosep, Montgomeryville, PA, U.S.A.). Fractions were collected at a flow rate of $2 \mathrm{ml}$ per min, and elution of root exudate components was monitored with a Shodex RI71 refractive index detector (Showa Denko, Tokyo, Japan). The high molecular weight material, referred to as purified pea root mucilage, eluted from this column in the void volume fractions. Fractions containing purified mucilage were pooled and lyophilized exhaustively to remove ammonium acetate by sublimation. The purified mucilage was weighed on a microbalance, and samples were taken directly for further fractionation or chemical analysis or dissolved in sterile distilled water at a concentration of $4 \mathrm{mg}$ per $\mathrm{ml}$ and stored at $-20^{\circ} \mathrm{C}$ for microbiological studies.

\section{Mucilage composition analysis.}

Neutral sugar and uronic acid composition was determined on $20-\mu \mathrm{g}$ samples of mucilage by the methanolysis- trimethylsilyl derivatization method of Chaplin (1982), as modified by Komalavilas and Mort (1989). Sugar-linkage composition was determined on $300-\mu \mathrm{g}$ samples of mucilage, according to the permethylation procedures described by Kvernheim (1987). Amino acid composition was determined by capillary zone electrophoresis on 6-aminoquinolyl-Nhydroxysuccinimidyl carbone-derivatized acid hydrolysate from $50-\mu \mathrm{g}$ samples of purified mucilage, as described by Zhang et al. (1998).

\section{Bacterial strains and growth studies.}

The bacteria tested for the ability to utilize pea root mucilage are listed in Table 4. Bacteria were cultured in TY liquid medium (per liter: $6.0 \mathrm{~g}$ of Bacto tryptone, $3.0 \mathrm{~g}$ of yeast extract, and $0.5 \mathrm{~g}$ of $\mathrm{CaCl}_{2} .2 \mathrm{H}_{2} \mathrm{O}$ ), with the appropriate antibiotic for $24 \mathrm{~h}$ at $28^{\circ} \mathrm{C}$, washed by centrifugation and then transferred to $\mathrm{NM}$ minimal salts medium (containing, per liter, 500 $\mathrm{mg}$ of $\mathrm{KH}_{2} \mathrm{PO}_{4}, 200 \mathrm{mg}$ of $\mathrm{MgSO}_{4} .7 \mathrm{H}_{2} \mathrm{O}, 14 \mathrm{mg}$ of FeSO 4.7 $\mathrm{H}_{2} \mathrm{O}, 9.6 \mathrm{mg}$ of citric acid, $505 \mathrm{mg}$ of $\mathrm{KNO}_{3}, 0.1 \mathrm{mg}$ of $\mathrm{CaCl}_{2}$ plus $1 \mathrm{ml}$ of Gotz vitamin stock, and $0.2 \mathrm{ml}$ of trace metal stock (Robinson et al. 1992). The bacteria were then starved for 3 days in the mineral salts medium to reduce internal nutrient reserves. Approximately $10^{6}$ starved cells were inoculated into NM minimal medium containing $1 \mathrm{mg}$ of a carbon source (glucose, purified mucilage, or a commercial polysaccharide) per ml. Samples were taken from the cultures at each time point, and the appropriate dilutions were prepared in water and plated on solid TY medium with an appropriate antibiotic using a Spiral plater (Spiral Systems, Cincinnati, $\mathrm{OH}$, U.S.A.). Colony-forming units were counted after incubating the plates at $28^{\circ} \mathrm{C}$ for $48 \mathrm{~h}$. Aliquots of the cultures also were plated on TY agar plates without antibiotics after completing each growth time-course experiment to detect possible contamination by other microorganisms. For treatments with naringenin or other flavonoids, a $1 \mathrm{mM}$ stock solution of naringenin in ethanol was added to the medium to give a final concentration of $1 \mu \mathrm{M}$, and the appropriate concentration of ethanol was added to the mineral salts medium control.

\section{Flavonoids.}

Naringenin, luteolin, and 4,7-dihydroxyl flavone were purchased from Extrasynthese (Z. I. La Rechassiere, Genay, France) and dissolved in appropriate solvents, as recommended by the manufacturer, at a concentration of $10 \mathrm{mM}$. The concentrated flavonoid stocks were then diluted to $1 \mathrm{mM}$

Table 4. Bacterial strains and plasmids

\begin{tabular}{|c|c|c|}
\hline Bacterial strains & Relevant characters & Source \\
\hline \multicolumn{3}{|l|}{ Rhizobium leguminosarum } \\
\hline 8002 & Field isolate from a Phaseolus vulgaris nodule. & Lamb et al. 1982 \\
\hline 8401 & Strain 8002 cured of its symbiotic plasmid, $\mathrm{Str}^{\mathrm{R}}$. & Downie et al. 1983 \\
\hline 4292 & Rif-398r derivative of strain 8002, contains pRP2JI. & Johnston et al. 1982; Lamb et al. 1982 \\
\hline \multicolumn{3}{|l|}{ Burkholderia cepacia } \\
\hline AMMDstr & Spontaneous str ${ }^{\mathrm{R}}$ derivative of AMMD (ATCC 52796). & Parke et al. 1991 \\
\hline \multicolumn{3}{|l|}{ Pseudomonas fluorescens } \\
\hline PRA25rif & Spontaneous rif ${ }^{\mathrm{R}}$ derivative of PRA25 (ATCC 53794). & Bowers and Parke 1993 \\
\hline \multicolumn{3}{|l|}{ Plasmids } \\
\hline pRL1JI & $\begin{array}{l}\text { Transmissible symbiotic plasmid from } R \text {. leguminosarum } 248 \text {, isolated from } \\
\text { nodule on Vicia faba. }\end{array}$ & Johnston et al. 1982 \\
\hline pRP2JI & $\begin{array}{l}\text { Transmissible symbiotic plasmid from } R \text {. leguminosarum bv. phaseoli } \\
8002 \text {, isolated from nodule on } P \text {. vulgaris. }\end{array}$ & Johnston et al. 1982 \\
\hline
\end{tabular}


working stocks in ethanol. For growth studies, the working stocks were added to the NM medium to give a final concentration of $1 \mu \mathrm{M}$.

\section{Polysaccharides.}

Pectin and larch arabiogalactan were obtained from Sigma Chemical (St. Louis, MO, U.S.A.). Purified arabinan, debranched arabinan, arabinoxylan, pectic galactan, xyloglucan, and rhamnogalacturonan were purchased from Megazyme (Sydney, NSW, Australia). Polysaccharide stock solutions were prepared by dissolving in sterile double-distilled water, to a final concentration of $4 \mathrm{mg}$ per $\mathrm{ml}$, and filter sterilizing. Pectic galactan and debranched arabinan stocks were sterilized by heating in a water bath at $65^{\circ} \mathrm{C}$ for $1 \mathrm{~h}$ because it was very difficult to pass them through a $0.2-\mu \mathrm{m}$ filter. In some cases, the polysaccharides were precipitated and washed with $70 \%$ ethanol to remove any low molecular weight materials that might be present. Growth on these precipitated polysaccharides was not significantly greater than on the unprecipitated polymers.

\section{Autolysis of root mucilage.}

The possible autolysis of mucilage by root enzymes in the mucilage preparations was investigated by mixing purified pea mucilage with buffer to a final concentration of $0.75 \mathrm{mg}$ per $\mathrm{ml}$. The mixture was filter sterilized and divided into four equal aliquots. Two aliquots were stored at $-80^{\circ} \mathrm{C}$ as controls, and an additional two were incubated at $37^{\circ} \mathrm{C}$ for 8 days, allowing possible autolytic cleavage of mucilage by root enzymes. The four samples were then rechromatographed on the HPLC gel filtration column.

\section{ACKNOWLEDGMENTS}

We thank A. Downie and J. Parke for providing the cultures and plasmids used in this study and S. Bauer and J. Scherf for technical assistance. This work was supported by grant 9501356 from the USDANRI Soils Biology program. Partial support for salaries, supplies, and publication costs was provided by state and federal funds appropriated to the Ohio Agricultural Research and Development Center, Ohio State University. OARDC manuscript HCS 00-15.

\section{LITERATURE CITED}

Anderson, A. J., Habibzadegah-Tari, P., and Tepper, C. S. 1988. Molecular studies on the role of a root surface agglutinin in adherence and colonization by Pseudomonas putida. Appl. Environ. Microbiol. 54:375-380.

Bacic, A., Moody, S. F., and Clarke, A. E. 1986. Structural analysis of secreted root slime from maize (Zea mays L.). Plant Physiol. 80:771777.

Bacic, A., Du, H., Stone, B. A., and Clarke, A. E. 1996. Arabinogalactan proteins: A family of cell-surface and extracellular matrix plant proteoglycans. Essays Biochem. 31:91-101.

Battisti, L., Lara, J. C., and Leigh, J. A. 1992. Specific oligosaccharide form of the Rhizobium meliloti exopolysaccharide promotes nodule invasion in alfalfa. Proc. Natl. Acad. Sci. USA 89:5625-5629.

Bowers, J. H., and Parke, J. L. 1993. Colonization of pea taproots by Pseudomonas fluorescens: Effect of soil temperature and bacterial motility. Soil Biol. Biochem. 25:1693-1701.

Callaham, D., and Torrey, J. 1981. The structural basis for infection of root hairs of Trifolium repens by Rhizobium. Can. J. Bot. 59:16471664.

Chaboud, A. 1983. Isolation, purification and chemical composition of maize root cap slime. Plant Soil 73:395-402.

Chaboud, A., and Rougier, M. 1984. Identification and localization of sugar components of rice (Oryza sativa L.) root cap mucilage. J. Plant Physiol. 116:323-330.

Chao, W., Li, R., and Chang, W. 1988. Effect of root agglutinin on microbial activities in the rhizosphere. Appl. Environ. Microbiol. 54:1838-1841.

Chaplin, M. F. 1982. A rapid and sensitive method for the analysis of carbohydrate components in glycoproteins using gas-liquid chromatography. Anal. Biochem. 123:334-341.

Cheng, H. P., and Walker, G. C. 1998. Succinoglycan is required for initiation and elongation of infection threads during nodulation of alfalfa by Rhizobium meliloti. J. Bacteriol. 180:5183-5191.

Dazzo, F. B. 1981. Bacterial attachment as related to cellular recognition in the Rhizobium-legume symbiosis. J. Supramol. Struct. Cell Biochem. 16:29-41.

Dazzo, F. B., and Hrabak, E. M. 1981. Presence of trifoliin A, a Rhizobium-binding lectin, in clover root exudate. J. Supramol. Struct. Cell Biochem. 16:133-138.

Djordjevic, S. P., Chen, H., Batley, M., Redmond, J. W., and Rolfe, B. G. 1987. Nitrogen fixation ability of exopolysaccharide synthesis mutants of Rhizobium sp. strain NGR234 and Rhizobium trifolii is restored by the addition of homologous exopolysaccharides. J. Bacteriol. 169:53-60.

Downie, J. A., Hombrecher, G., Ma, Q. S., Knight, C. D., Wells, B., and Johnston, A. W. 1983. Cloned nodulation genes of Rhizobium leguminosarum determine host-range specificity. Mol. Gen. Genet. 190:359365.

Fincher, G. B., Stone, B. A., and Clarke, A. E. 1983. Arabinogalactanproteins: Structure, biosynthesis, and function. Annu. Rev. Plant Physiol. 34:47-70.

Finnie, C., Zorreguieta, A., Hartley, N. M., and Downie, J. A. 1998. Characterization of Rhizobium leguminosarum exopolysaccharide glycanases that are secreted via a type I exporter and have a novel heptapeptide repeat motif. J. Bacteriol. 180:1691-1699.

Gollotte, A., Gianinazzi-Pearson, V., and Gianinazzi, S. 1995. Immunodetection of infection thread glycoprotein and arabinogalactan protein in wild type Pisum sativum (L.) or an isogenic Mycorrhizaresistant mutant interacting with Glomus mosseae. Symbiosis 18:6985.

Gonzalez, J. E., Reuhs, B. L., and Walker, G. C. 1996. Low molecular weight EPS II of Rhizobium meliloti allows nodule invasion in Medicago sativa. Proc. Natl. Acad. Sci. USA 93:8636-8641.

Greaves, D. J., and Darbyshire, J. F. 1972. The ultrastructure of the mucilaginous layer on plant roots. Soil Biol. Biochem. 4:443-449.

Greenland, D. J. 1979. The physics and chemistry of the soil root interface: Some comments. Pages 83-98 in: The Soil-Root Interface. J. L. Harley and R. S. Russell, eds. Academic Press, London.

Hartwig, U. A., Joseph, C. M., and Phillips, D. A. 1991. Flavonoids released from alfalfa seeds enhance growth rate of Rhizobium meliloti. Plant Physiol. 95:797-803.

Hawes, M. C., and Brigham, L. A. 1992. Impact of root border cells on microbial populations in the rhizosphere. Adv. Plant Pathol. 8:119148.

Hazlewood, G. P., and Gilbert, H. J. 1998. Structure and function analysis of Pseudomonas plant cell wall hydrolases. Prog. Nucleic Acid Res. Mol. Biol. 61:211-241.

Horst, W. J., Wagner, A., and Marshner, H. 1982. Mucilage protects root meristems from aluminum injury. Z. Pflanzenphysiol 105:435-444.

Jimenez-Zurdo, J. I., Mateos, P. F., Dazzo, F. B., and Martinez-Molina, E. 1996. Cell-bound cellulase and polygalacturonase production by Rhizobium and Bradyrhizobium species. Soil Biol. Biochem. 28:917921.

Johnston, A. W., Beynon, J. L., Buchanan-Wollaston, A. V., Stechell, S. M., Hirsch, A. M., and Beringer, J. E. 1978. High frequency transfer of nodulation ability between strains and species of Rhizobium. Nature 276:634-636.

King, E. B., and Parke, J. L. 1993. Biocontrol of Aphanomyces root rot and Pythium damping-off by Pseudomonas cepacia AMMD on four pea cultivars. Plant Dis. 77:1185-1188.

Komalavilas, P., and Mort, A. J. 1989. The acetylation at O-3 of galacturonic acid in the rhamnose-rich region of pectins. Carbohydr. Res. 189:261-272.

Kuo, Y. H., Lambein, F., Ikegami, F., and Parijs, R. V. 1982. Isoxazolin5-ones and amino acids in root exudates of pea and sweet pea seedlings. Plant Physiol. 70:1283-1289. 
Kvernheim, A. L. 1987. Methylation analysis of polysaccharides with butyllithium in dimethylsulfoxide. Acta Chem. Scand. Ser. B B41:150-152.

Leigh, J. A., and Walker, G. C. 1994. Exopolysaccharides of Rhizobium: Synthesis, regulation and symbiotic function. Trends Genet. 10:63-67.

Long, S. 1996. Rhizobium symbiosis: Nod factors in perspective. Plant Cell 8:1885-1898.

Majewska-Sawka, A., and Nothnagel, E. A. 2000. The multiple roles of arabinogalactan proteins in plant development. Plant Physiol. 122:310 .

Mary, B., Fresneau, C., Morel, J. L., and Mariotti, A. 1993. C and N cycling during decomposition of root mucilage, roots and glucose in soil. Soil Biol. Biochem. 25:1005-1014.

Mateos, P. F., Jimenez-Zurdo, J. I., Chen, J., Squartini, A. S., Haack, S. K., Martinez-Molina, E., Hubbell, D. H., and Dazzo, F. B. 1992. Cellassociated pectinolytic and cellulolytic enzymes in Rhizobium leguminosarum biovar trifolii. Appl. Environ. Microbiol. .58:1816-1822.

McCully, M. E. 1995. How do real roots work? Some new views of root structure. Plant Physiol. 109:1-6.

Mensch, M., Morel, J. L., and Guckert, A. 1987. Metal binding properties of high molecular weight soluble exudates from maize (Zea mays L.) roots. Biol. Fertil. Soils 3:165-169.

Moody, S. F., Clarke, A. E., and Bacic, A. 1988. Structural analysis of secreted slime from wheat and cowpea roots. Phytochemistry 27:2857-2861

Moore, R., Evans, M. L., and Fondern, W. M. 1990. Inducing gravitropic curvature of primary roots of Zea mays cv. Ageotropic. Plant Physiol. 92:310-315.

Morel, J. L., Andreuz, F., Habib, L., and Guckert, A. 1987. Comparison of the adsorption of maize root mucilage and polygalacturonic acid on montmorillonite monoionic to divalent lead and cadmium. Biol. Fertil. Soils 5:13-17.

Morel, J. L., Habib, L., Plantureaux, S., and Guckert, A. 1991. Influence of maize root mucilage on soil aggregate stability. Plant Soil 136:111-
119

Parke, J. L., Rand, R. E., Joy, A. E., and King, E. B. 1991. Biological control of Pythium damping-off and Aphanomyces root of peas by application of Pseudomonas cepacia or P. fluorescens to seed. Plant Dis. 75:987-992.

Perkins, S. K., Calvert, H. E., and Bauer, W. D. 1984. CryoSEM of the soybean rhizoplane. Pages 323-324 in: 42nd Annual Meeting of Electron Microscopy Society of America. G. W. Bailey, ed. San Francisco Press, San Francisco.

Peters, N. K., and Verma, D. P. S. 1990. Phenolic compounds as regulators of gene expression in plant-microbe relations. Mol. Plant Microbe Interact. 3:4-8.

Robinson, J. B., Tuovinen, O. H., and Bauer, W. D. 1992. Role of divalent cations in the subunit associations of complex flagella from Rhizobium meliloti. J. Bacteriol. 174:3896-3902.

Sims, I. M., Middleton, K., Lane, A. G., Cairns, A. J., and Bacic, A 2000. Characterisation of extracellular polysaccharides from suspension cultures of members of the poaceae. Planta 210:261-268.

Van Egeraat, A. W. S. M. 1975. Changes in free ninhydrin-positive compounds of young pea plants as affected by different nutritional and environmental conditions. Plant Soil 42:15-36.

York, G. M., and Walker, G. C. 1998. The Rhizobium meliloti ExoK and ExsH glycanases specifically depolymerize nascent succinoglycan chains. Proc. Natl. Acad. Sci. USA 95:4912-4917.

Zablackis, E., Huang, J., Muller, B., Darvill, A. G., and Albersheim, P. 1995. Characterization of the cell-wall polysaccharides of Arabidopsis thaliana leaves. Plant Physiol. 107:1129-1138.

Zhang, Z. 1998 Changes in homogalacturonans, polygalacturonase activities, and cell wall linked proteins during cotton cotyledon expansion. $\mathrm{PhD}$ thesis. Oklahoma State University, Stillwater, OK, U.S.A.

Zorreguieta, A., Finnie, C., and Downie, J. A. 2000. Extracellular glycanases of Rhizobium leguminosarum are activated on the cell surface by an exopolysaccharide-related component. J. Bacteriol. 182:1304-1312. 